\title{
Demands for Telenursing-Based Long-Term Care Among Disabled Older Adults in Qingdao, China: A Cross-Sectional Study
}

\author{
Yu Wu $\mathbb{1 D}^{1,2, *}$ \\ Yuxiu Liu $\mathbb{D}^{3, *}$ \\ Zhe Su${ }^{2}$ \\ Songwei Sun $\mathbb{D}^{1}$ \\ Cuiping Liu' \\ Wei Ding ${ }^{2}$ \\ Yufang $\mathrm{Gao}^{2}$ \\ 'School of Nursing, Qingdao University, \\ Qingdao, People's Republic of China; \\ ${ }^{2}$ The Affiliated Hospital of Qingdao \\ University, Qingdao, People's Republic of \\ China; ${ }^{3}$ School of Nursing, Weifang \\ Medical University, Weifang, People's \\ Republic of China
}

*These authors contributed equally to this work
Correspondence: Yufang Gao

The Affiliated Hospital of Qingdao

University, Qingdao, 266000, People's

Republic of China

Tel +86-19863737553

Email gaoyufang0612@163.com
Purpose: The purpose of the present study was to investigate the current status of and factors influencing the demands for telenursing-based long-term care in disabled older adults. Methods: In this cross-sectional study, data from 213 participants from five districts of Qingdao, China, were investigated using multistage stratified sampling. The assessment scale of the long-term care demands level and the questionnaire of the demands of telenursingbased long-term care for disabled older adults were used to estimate the demands for telenursing-based long-term care for older adults with disabilities in Qingdao.

Results: Of the participants, $60.51 \%$ were willing to receive telenursing-based long-term care. The item with the highest score was "Internet +" information management and first aid $(3.77 \pm 0.71)$; the item with the lowest score was "Internet + " daily care $(2.97 \pm 0.72)$. Average family income $(P<0.001)$, age $(P=0.004)$ and educational level $(P=0.003)$ were significant factors influencing the demands for telenursing-based long-term care.

Conclusion: Disabled older adults had a high demand for telenursing-based long-term care. Urgent actions are needed to integrate telenursing with long-term care as soon as possible. In the development of telenursing-based long-term care, it is necessary to fully consider the average family income, age and educational level of disabled older adults.

Keywords: telenursing, long-term care, disabled older adults, demands

\section{Introduction}

Due to declines in birth rates and increases in average life expectancy, it is estimated that 2.1 billion people will be over 60 years old by 2050 worldwide. ${ }^{1}$ The growing number of older adults has become an important global social issue. According to the seventh national census in China, the number of people in the population aged 60 and over was 264 million, ${ }^{2}$ of whom approximately 40 million were disabled and semidisabled older adults. ${ }^{3}$ There were 2.043 million people aged 60 and over in Qingdao, accounting for $20.28 \%$ of the population in total. ${ }^{4}$ Qingdao has become one of the cities with a strong trend of aging in China.

In general, disability refers to the loss or limitation of a person's main activity or activities of daily living and is an important indicator of individual health measurement..$^{5}$ Older adults with disabilities in the population aged 60 and above had functional deficits caused by chronic diseases, physical injuries, and mental dysfunctions, that is, older adults with impaired activities of daily living. ${ }^{6}$ To meet the nursing needs of disabled older adults, the system of long-term care insurance has been explored gradually in China. In 2020, “The Guiding Opinions 
on Expanding the Pilot of Long-term Care Insurance System", published by the National Healthcare Security Administration and Ministry of Finance of the People's Republic of China, ${ }^{7}$ indicated that long-term care insurance could provide medical care, daily care, palliative care and other types of care for disabled older adults to reduce the burden of informal caregivers and improve the physical condition of disabled older adults. Longterm care can be interpreted as providing long-term assistance to people who cannot completely take care of themselves in daily activities. ${ }^{8}$ Daily activities include activities of daily living (ADL), such as bathing or dressing, and instrumental activities of daily living (IADL), such as shopping or handling housework. ${ }^{9}$ Qingdao was one of the first pilot cities in China to implement the system of long-term care insurance. Currently, long-term care facilities mainly provide home care, institutional care and day care for disabled older adults in Qingdao, China. Disabled older adults can choose among the three types of care according to the level of disability to decrease wasted medical resources to a certain extent.

At the same time, the National Conference on Medical Management indicated the development of home-based care and telenursing for older adults. ${ }^{10}$ With the rapid development of information technology and medical technology, telenursing will be a new model of nursing services in the future. ${ }^{11}$ Telenursing-based long-term care was defined to support and improve long-term care through electronic information and telecommunications technologies. Chief among the changes was the added use of telenursing consultation, telereferral, a remote one-button emergency caller, etc., to provide intelligent care for disabled older adults when they are separated by a distance. Research has shown that telenursing not only has no limitation of time and space in nursing care ${ }^{12}$ but also effectively reduces the shortage of nursing staff. Many countries are trying to develop telenursing by improving information technology ${ }^{13}$ and having applied telenursing to people with disabilities, chronic obstructive pulmonary disease and cancer. ${ }^{14-17}$ However, the vast majority of long-term care in China was provided on the spot, with a lack of telenursing, such as remote consultation and remote one-button emergency calling. A qualitative research showed that disabled older adults and their families expressed a higher demand for telenursing. ${ }^{18} \mathrm{It}$ is urgent to combine telenursing and long-term care to meet the demands of disabled older adults.
Many studies have found that personal status, including gender, age, education and physical health, is associated with the need for digital health technology among disabled older adults. ${ }^{19-21}$ Disabled older adults who are female, ${ }^{22-24}$ have greater education ${ }^{23-25}$ and physical conditions ${ }^{26-28}$ are more likely to use the internet. It is more difficult to use the internet for disabled older adults who are suffering from physical and functional disabilities. ${ }^{21}$ Family status is also an important aspect of the demand for long-term care by disabled older adults. ${ }^{29}$ Studies have shown that accessibility to informal support influences older adults' willingness to engage in long-term care. ${ }^{20}$ Older adults prefer to stay at home with their families rather than staying in long-term care institutions. Financial status can also influence choices regarding the needs of disabled older adults. ${ }^{30}$ In situations where nursing services are not free, when the monthly income of disabled older adults is large enough, they can have more choices of nursing services.

Previous studies on home-based care have mainly paid attention to the demands for long-term care, telenursing, home-based care, etc. ${ }^{31,32}$ There have been limited studies concerning the demands for telenursing-based long-term care for older adults. Although disabled older adults have reported that the needs and expenses of telenursing were high, the government and society have paid little attention to this serious problem. Thus, the main objective of the current cross-sectional study was to investigate disabled older adults' demand for telenursing-based long-term care and the influencing factors to provide information for nursing managers and decision-makers.

\section{Methods}

\section{Study Design}

This cross-sectional study was conducted among disabled older adults in the period from January to April 2021 from twenty communities in the Shinan, Shibei, Chengyang, Xihaian and Licang Districts of Qingdao, China, which were selected by means of multistage stratified sampling. First, Shinan, Shibei, Chengyang, Xihaian and Licang Districts were selected; second, four communities were selected from each district; third, at least ten participants were selected from each community. Furthermore, the influencing factors investigated in this cross-sectional study were all taken from previous studies. The factors investigated mainly include personal status (gender, age, education level, chronic diseases, level of disability, selfassessment of health), family status (informal caregiver, 
average family income) and financial status (acceptable monthly nursing expenses, the impact of the government policy on service selection).

\section{Study Subjects}

The inclusion criteria for disabled older adults were as follows: (1) being at least 60 years of age; (2) having a level 3 to 5 disability; (3) being a disabled older adult or their caregiver (at least three months of caregiving ${ }^{18}$ ) with the ability to operate devices such as smartphones or computers; and (4) living in a residence for more than one year. The exclusion criteria were as follows: (1) having a mental disorder; (2) experiencing communication difficulties and having a level of education lower than elementary school; and (3) having an attitude of rejection toward telenursing-based long-term care.

\section{Sample Size}

The sample size was calculated according to the multivariate linear regression equation, and the sample size could be at least 5 to 10 times the number of variables in the equation. ${ }^{33}$ There were 10 independent variables that were introduced into the equation. Thus, the sample size was at least 50-100, and considering the unavailability and a nonresponse rate of $20 \%$, the amount of required sample was 120 . In the present study, there were 352 participants in total.

\section{Measures}

The measurement tools used for data collection included the following three sections: (1) sociodemographic characteristics, (2) a scale for assessing the level of long-term care demands of Qingdao, and (3) a questionnaire on the demands for telenursing-based long-term care for disabled older adults.

\section{Sociodemographic Characteristics}

The demographic data included gender, age, education level, informal caregiver status, chronic diseases, average family income, acceptable monthly nursing expenses, the impact of the government policy on service selection, level of disability, and self-assessment of health.

\section{Scale for Assessing the Level of Long-Term Care Demands of Qingdao}

The level of disability was measured using the scale for assessing the level of long-term care demands of Qingdao administered by the Qingdao Municipal Medical Insurance Bureau. ${ }^{34}$ This scale included 22 items that were divided into four dimensions: Activities of daily living, mental status, sensory and communication, and social involvement. The levels of disability ranged from 0 to 5 . The assessment results were consistent with the result of the Abilities Assessment for the Older Adult issued by the Ministry of Civil Affairs of the People's Republic of China in 2013. Level 0 indicated intact ability; level 1, mild disability; levels 2 to 3 , moderate disability; and levels 4 to 5 , severe disability.

\section{Questionnaire on the Demands for Telenursing-Based Long-Term Care for Disabled Older Adults}

This questionnaire compiled by researchers was based on a literature review and included items such as the status of long-term care, demands for telenursing, and disabled older adults' needs. This questionnaire was intended to investigate the demands for telenursing-based long-term care for older adults with disabilities. This questionnaire included 27 items that were grouped into seven dimensions, ie, "Internet + " information management and first aid (3 items), "Internet +" medical care (4 items), "Internet +" traditional Chinese medicine nursing (3 items), "Internet +" health consultation (5 items), "Internet +" rehabilitation training (3 items), "Internet +" spiritual consolation (5 items), and "Internet + " daily care (4 items). Each item was assessed with a five-point Likert scale that ranged from 1 ("extremely disagree") to 5 ("extremely agree"). High scores show high demands for telenursingbased long-term care for disabled older adults. This questionnaire had a composite Cronbach's $\alpha$ of 0.891 , and Cronbach's $\alpha$ for the seven dimensions ranged from 0.708 to 0.851 . The content validity was 0.917 , indicating that this questionnaire had good reliability and validity.

\section{Data Collection}

With the consent of disabled older adults and their family members, researchers were accompanied by home-based nurses in nursing facilities to complete the door-to-door investigation. Since most disabled older adults had not yet heard of "telenursing-based long-term care", researchers introduced content related to telenursing-based long-term care first and then asked about their willingness to accept it. If the questionnaire could not be filled out by disabled older adults themselves due to disability or other reasons, they completed it with the assistance of researchers. The questionnaire was collected and checked on the spot, and illogical questionnaires were eliminated to ensure the 
quality of the questionnaire data. Of the 352 questionnaires in this study in total, 213 respondents were willing to accept telenursing-based long-term care, representing a rate of $60.51 \%$.

\section{Data Analysis}

All data were analyzed by SPSS 25.0 software. Categorical data are presented as frequencies and percentages, and measurement data are presented as means and standard deviations. Statistical inference was conducted through single-factor analysis and multivariate linear regression, and $P<0.05$ was required for statistical significance.

\section{Results}

While 213 disabled older adults had a strong willingness to use telenursing-based long-term care, others refused to accept this service. Thus, this study only analyzed the demands of participants who were willing to use telenursing-based long-term care.

\section{Demographic Characteristics of the Participants}

A total of 213 participants from twenty communities completed the questionnaires in this study, with a gender distribution of 1:1. Disabled older adults were distributed unevenly among the different age brackets; the share of disabled older adults aged over 80 was the lowest $(16.43 \%)$, and the share of those aged 60 69 years old was the highest $(42.72 \%)$. Among these participants, 28 disabled older adults had received a primary education, and 19 disabled older adults had at least an undergraduate education. According to the scale for assessing the level of long-term care demands of Qingdao, there were 151 older adults with disability level 3 (Table 1).

\section{Scores for the Demands for Telenursing-Based Long-Term Care}

Table 2 shows the demands for telenursing-based longterm care for all disabled older adults. The questionnaire included seven dimensions; the demand scores for "Internet +" information management and first aid (3.77 \pm 0.71 ) were the highest, and those for "Internet + " daily care $(2.97 \pm 0.72)$ were the lowest. However, the score for medication reminders $(3.14 \pm 0.77)$ was relatively high.

\section{Single-Factor Analysis of the Demands for Telenursing-Based Long-Term Care for Disabled Older Adults}

Single-factor analysis was conducted with the total scores indicating the demand for telenursing-based long-term care for disabled older adults as the dependent variable and with demographic characteristics as the independent variables. The results demonstrated that the scores indicating the demand for telenursing-based long-term care for disabled older adults differed significantly with respect to age, education level, informal caregiver, chronic diseases, average family income, acceptable monthly nursing expenses and level of disability $(P<0.05)$. However, there was no significant difference in the demand scores with respect to gender, the impact of the government policy on service selection and self-assessment of health $(P>0.05)$ (Table 3$)$.

\section{Multiple Linear Regression Analysis of the Impact of the Demands for Telenursing-Based Long-Term Care}

Multiple linear regression was used to determine the relationship between the demographic characteristics of the participants and the scores indicating the demands for telenursing-based long-term care. The total scores representing the demands for telenursing-based long-term care were regarded as dependent variables, and statistically significant variables in the single factor analysis were considered the independent variables. The variance inflation factors (VIF) were between 1.142 and 1.411 in this study, which showed that there was no obvious problem with collinearity among the variables entered into the regression equation. When the independent variables of age, education level, informal caregiver, chronic diseases, average family income, acceptable monthly nursing expenses and level of disability were substituted into the regression equation with scores representing the demands for telenursing-based long-term care for disabled older adults as the dependent variable, the results showed a multiple correlation coefficient of 0.479 and a coefficient of determination $\left(\mathrm{R}^{2}\right)$ of 0.229 . Thus, these independent variables could effectively explain $22.9 \%$ of the variance in the scores representing the demands for telenursing-based long-term care for disabled older adults. There were significant influencing factors in the multiple linear regression: average family income $(P<0.001)$, age $(P=0.004)$ and educational level $(P=0.003)$ (Table 4). 
Table I Demographic Characteristics of the Participants $(n=2 \mid 3)$

\begin{tabular}{|c|c|}
\hline Variable & n (\%) \\
\hline \multicolumn{2}{|l|}{ Gender } \\
\hline Male & $100(46.95)$ \\
\hline Female & $113(53.05)$ \\
\hline \multicolumn{2}{|l|}{ Age (years) } \\
\hline $60 \sim 69$ & 91 (42.72) \\
\hline 70 79 & $87(40.85)$ \\
\hline$\geq 80$ & $35(16.43)$ \\
\hline \multicolumn{2}{|l|}{ Educational level } \\
\hline Primary school & $28(13.15)$ \\
\hline Middle school and technical secondary school & $122(57.28)$ \\
\hline High school and junior college & $44(20.66)$ \\
\hline Undergraduate degree or higher & $19(8.92)$ \\
\hline \multicolumn{2}{|l|}{ Informal caregiver } \\
\hline Spouse & $85(39.91)$ \\
\hline Nanny & $23(10.80)$ \\
\hline Children & $87(40.85)$ \\
\hline No caregiver & $6(2.82)$ \\
\hline Others & $12(5.63)$ \\
\hline \multicolumn{2}{|l|}{ Chronic disease status } \\
\hline$\leq \mathrm{I}$ & $44(20.66)$ \\
\hline 2 & $69(32.39)$ \\
\hline 3 & $57(26.76)$ \\
\hline 4 & $18(8.45)$ \\
\hline$\geq 5$ & $25(11.74)$ \\
\hline \multicolumn{2}{|l|}{ Average family income (yuan) } \\
\hline$<1000$ & $8(3.76)$ \\
\hline $1000-2000$ & $19(8.92)$ \\
\hline $200 I-3000$ & $63(29.58)$ \\
\hline $300 I-4000$ & $74(34.74)$ \\
\hline$>4000$ & $49(23.00)$ \\
\hline \multicolumn{2}{|l|}{ Acceptable monthly nursing expenses (yuan) } \\
\hline$<100$ & $27(12.68)$ \\
\hline $100-400$ & $55(25.82)$ \\
\hline $40 I-700$ & $77(36.15)$ \\
\hline $701-1000$ & $24(11.27)$ \\
\hline$>1000$ & $30(14.08)$ \\
\hline \multicolumn{2}{|l|}{ Impact of the government policy on service selection } \\
\hline Not at all & 7 (3.29) \\
\hline Not & $31(14.55)$ \\
\hline Commonly & $69(32.39)$ \\
\hline Partial impact & $72(33.80)$ \\
\hline Certain impact & $34(15.96)$ \\
\hline \multicolumn{2}{|l|}{ Level of disability ${ }^{\mathrm{a}}$} \\
\hline Level 3 & $15 \mid(70.89)$ \\
\hline Level 4 & $44(20.66)$ \\
\hline Level 5 & $18(8.45)$ \\
\hline
\end{tabular}

(Continued)
Table I (Continued).

\begin{tabular}{|l|l|}
\hline Variable & n (\%) \\
\hline Self-assessment of health status & \\
Very poor & $13(6.10)$ \\
Poor & $63(29.58)$ \\
Commonly & $119(55.87)$ \\
Well & $18(8.45)$ \\
\hline
\end{tabular}

Notes: ${ }^{\text {T}}$ The level of disability was evaluated through 22 items that were divided into four aspects: activities of daily living ( 10 items), mental status ( 3 items), sensory and communication (4 items), and social involvement (5 items). Each aspect is evaluated int levels 0 to 3 according to the relative item score. The level 3 disability means that activities of daily living are at level 2 and that the level is below 2 for any one of the following: mental status, sensory and communication, and social involvement. The level 4 disability means that activities of daily living are at level 2 and that mental status, sensory and communication, and social involvement are all level 2 or any one of them is level 3; alternatively, activities of daily living are at level 3 , and the scores for activities of daily living are $25-40$ points, with the level of any one of the remaining three aspects being 2 or less. The level 5 disability means that activities of daily living are at level 3 and that the scores for activities of daily living are 25-40 points; the levels of the remaining three aspects are all 2, or any one of them is level 3 ; activities of daily living are at level 3 , and the scores for activities of daily living are 0-20 points; or the adult is in a coma or has a diagnosis of severe dementia.

\section{Discussion}

\section{High Demands for Telenursing-Based Long-Term Care for Disabled Older Adults}

This cross-sectional study aimed to investigate the current status of demands for telenursing-based long-term care for older adults with disabilities in Qingdao, China. The results demonstrated that disabled older adults had great demands for telenursing-based long-term care. The item with the highest score was "Internet +" information management and first aid, followed by the scores for "Internet +" medical care. This result not only reflected that disabled older adults had great expectations for "Internet +" information management and first aid but also reflected that this measure could play an important role in facilitating the development of telenursing-based long-term care. In contrast, participants had the lowest demands for "Internet +" daily care. Many disabled older adults were well taken care of by their families. Second, long-term care included door-to-door daily care, ${ }^{35}$ which led to low demands for telenursing-based long-term care for disabled older adults.

The demands for "Internet + " traditional Chinese medicine nursing were at middle or higher levels, which may be connected with people's gradually increasing attention to traditional Chinese medicine. The "Outline of China's Nursing Development Plan (2016-2020)"36 proposed robustly developing traditional 
Table 2 The Scores and Rankings for the Needs of Disabled Older Adults for Telenursing-Based Long-Term Care ( $\mathrm{n}=2$ I3)

\begin{tabular}{|c|c|c|}
\hline Item & Mean \pm SD & Sequence \\
\hline "Internet +" spiritual consolation & $3.15 \pm 0.78$ & $6^{\mathrm{a}}$ \\
\hline Intelligent monitoring & $3.64 \pm 0.89$ & 4 \\
\hline Visual call & $3.16 \pm 0.74$ & 17 \\
\hline Online psychological counseling & $3.13 \pm 0.75$ & 19 \\
\hline Online palliative care & $2.95 \pm 0.68$ & 25 \\
\hline Virtual entertainment & $2.89 \pm 0.60$ & 26 \\
\hline "Internet +" health consultation & $3.23 \pm 0.75$ & $4^{\mathrm{a}}$ \\
\hline Remote guidance on home safety prevention & $3.45 \pm 0.75$ & 7 \\
\hline Remote guidance in self-help & $3.34 \pm 0.86$ & 9 \\
\hline Teletraining on care skills & $3.32 \pm 0.75$ & 11 \\
\hline Remote consultation on the policy of long-term care insurance & $3.09 \pm 0.63$ & 20 \\
\hline Remote consultation with assistive devices & $2.96 \pm 0.62$ & 23 \\
\hline "Internet +" rehabilitation training & $3.17 \pm 0.72$ & $5^{\mathrm{a}}$ \\
\hline Remote education in rehabilitation videos & $3.27 \pm 0.73$ & 14 \\
\hline Remote supervision of rehabilitation & $3.26 \pm 0.76$ & 15 \\
\hline Rehabilitation in the virtual environment & $2.98 \pm 0.63$ & 21 \\
\hline "Internet +" medical care & $3.43 \pm 0.78$ & $2^{\mathrm{a}}$ \\
\hline Telereferral & $3.64 \pm 0.65$ & 4 \\
\hline Telenursing consultation & $3.57 \pm 0.71$ & 6 \\
\hline Remote monitoring of vital signs & $3.31 \pm 0.81$ & 12 \\
\hline Online appointment & $3.20 \pm 0.85$ & 16 \\
\hline "Internet +" traditional Chinese medicine nursing & $3.32 \pm 0.70$ & $3^{\mathrm{a}}$ \\
\hline Remote consultation with traditional Chinese medicine nursing & $3.35 \pm 0.72$ & 8 \\
\hline Remote supervision with traditional Chinese medicine nursing & $3.33 \pm 0.69$ & 10 \\
\hline Remote education via traditional Chinese medicine nursing & $3.28 \pm 0.70$ & 13 \\
\hline "Internet +" daily care & $2.97 \pm 0.72$ & $7^{\mathrm{a}}$ \\
\hline Remote medication reminder & $3.14 \pm 0.77$ & 18 \\
\hline Online food delivery & $2.98 \pm 0.77$ & 21 \\
\hline Remote dietary guidance & $2.96 \pm 0.72$ & 23 \\
\hline Online reminder of important days & $2.82 \pm 0.59$ & 27 \\
\hline "Internet +" information management and first aid & $3.77 \pm 0.71$ & $\mathrm{I}^{\mathrm{a}}$ \\
\hline Remote one-button emergency caller & $3.83 \pm 0.69$ & I \\
\hline Family management account & $3.76 \pm 0.79$ & 2 \\
\hline Emergency card (scan QR code to obtain basic information) & $3.74 \pm 0.63$ & 3 \\
\hline
\end{tabular}

Notes: ${ }^{a}$ Is the sorting of mean scores for demands in the different dimensions. (The demands for each item are evaluated on a 5-point scale of importance, where I stands for "extremely disagree" and 5 stands for "extremely agree").

Chinese medicine nursing, continuously improving the level of traditional Chinese medicine nursing and fully reflecting its characteristics and advantages. In recent years, traditional Chinese medicine nursing has played an increasing role in disease treatment and prevention and has been widely recognized by people. ${ }^{37}$ Guohua Zheng showed that Baduanjin qigong training not only increased the immunity of older adults but also improved their mood and confidence. ${ }^{38}$ Therefore, it was recommended to integrate traditional Chinese medicine nursing with long-term care as soon as possible to delay the disability of older adults to a certain extent.

\section{Factors Influencing the Demands for Telenursing-Based Long-Term Care in Disabled Older Adults}

In the present study, the older the disabled older adults were, the higher their demands for telenursing-based longterm care, which was similar to the results in the study by Katarina Baudin et al. ${ }^{39}$ The telenursing-based long-term care in this study was based on the intelligent care represented by "Internet+". Older adults in China had different levels of difficulties in adapting to intelligent technology, and the physical functions of disabled older adults gradually declined with age, which affected their needs to 
Table 3 Single-Factor Analysis of the Demands for TelenursingBased Long-Term Care for Disabled Older Adults $(n=2 \mid 3)$

\begin{tabular}{|c|c|c|c|}
\hline Variable & Mean \pm SD & $t / F / \chi^{2}$ & $P$ \\
\hline \multicolumn{4}{|l|}{ Gender } \\
\hline Male & $88.99 \pm 9.07$ & $0.937^{\mathrm{a}}$ & 0.350 \\
\hline Female & $87.77 \pm 9.83$ & & \\
\hline \multicolumn{4}{|l|}{ Age (years) } \\
\hline $60 \sim 69$ & $88.11 \pm 8.66$ & $5.637^{\mathrm{b}}$ & 0.004 \\
\hline $70 \sim 79$ & $86.74 \pm 8.79$ & & \\
\hline$\geq 80$ & $92.94 \pm 9.52$ & & \\
\hline \multicolumn{4}{|l|}{ Educational level } \\
\hline Primary school & $90.25 \pm 9.10$ & $3.774^{b}$ & 0.011 \\
\hline Middle school and technical & $88.85 \pm 9.58$ & & \\
\hline secondary school & $8859+817$ & & \\
\hline $\begin{array}{l}\text { High school and junior } \\
\text { college }\end{array}$ & $88.59 \pm 8.17$ & & \\
\hline $\begin{array}{l}\text { Undergraduate degree or } \\
\text { higher }\end{array}$ & $81.68 \pm 10.19$ & & \\
\hline \multicolumn{4}{|l|}{ Informal caregiver } \\
\hline Spouse & $91.19 \pm 7.15$ & $11.570^{c}$ & 0.021 \\
\hline Nanny & $87.74 \pm 10.19$ & & \\
\hline Children & $85.99 \pm 10.37$ & & \\
\hline No caregiver & $90.17 \pm 4.31$ & & \\
\hline Others & $85.50 \pm 12.87$ & & \\
\hline \multicolumn{4}{|l|}{ Chronic disease status } \\
\hline$\leq 1$ & $88.36 \pm 6.29$ & $9.766^{c}$ & 0.045 \\
\hline 2 & $90.83 \pm 6.83$ & & \\
\hline 3 & $86.60 \pm 12.32$ & & \\
\hline 4 & $84.56 \pm 10.95$ & & \\
\hline$\geq 5$ & $88.16 \pm 10.73$ & & \\
\hline \multicolumn{4}{|l|}{ Average family income (yuan) } \\
\hline$<1000$ & $86.13 \pm 8.01$ & $35.652^{c}$ & $<0.001$ \\
\hline $1000-2000$ & $88.37 \pm 9.92$ & & \\
\hline $200 \mathrm{I}-3000$ & $82.27 \pm 10.78$ & & \\
\hline $300 I-4000$ & $91.84 \pm 6.74$ & & \\
\hline$>4000$ & $91.22 \pm 7.27$ & & \\
\hline \multicolumn{4}{|l|}{$\begin{array}{l}\text { Acceptable monthly nursing } \\
\text { expenses (yuan) }\end{array}$} \\
\hline$<100$ & $88.70 \pm 8.69$ & $2.699^{\mathrm{b}}$ & 0.032 \\
\hline $100-400$ & $86.60 \pm 9.19$ & & \\
\hline $40 I-700$ & $89.53 \pm 10.15$ & & \\
\hline $701-1000$ & $84.33 \pm 9.89$ & & \\
\hline$>1000$ & $91.37 \pm 7.19$ & & \\
\hline \multicolumn{4}{|l|}{$\begin{array}{l}\text { Impact of the government } \\
\text { policy on service selection }\end{array}$} \\
\hline Not at all & $92.14 \pm 8.26$ & $0.929^{\mathrm{b}}$ & 0.448 \\
\hline Not & $89.39 \pm 9.36$ & & \\
\hline Commonly & $89.26 \pm 8.02$ & & \\
\hline Partial impact & $87.18 \pm 10.61$ & & \\
\hline
\end{tabular}

(Continued)
Table 3 (Continued).

\begin{tabular}{|c|c|c|c|}
\hline Variable & Mean士SD & $t / F / \chi^{2}$ & $P$ \\
\hline Certain impact & $87.21 \pm 10.02$ & & \\
\hline \multicolumn{4}{|l|}{ Level of disability } \\
\hline Level 3 & $87.94 \pm 9.34$ & $4.015^{b}$ & 0.019 \\
\hline Level 4 & $91.34 \pm 8.92$ & & \\
\hline Level 5 & $84.39 \pm 10.39$ & & \\
\hline \multicolumn{4}{|c|}{$\begin{array}{l}\text { Self-assessment of health } \\
\text { status }\end{array}$} \\
\hline Very poor & $88.38 \pm 9.54$ & $1.844^{\mathrm{b}}$ & 0.140 \\
\hline Poor & $90.16 \pm 8.66$ & & \\
\hline Commonly & $87.96 \pm 9.69$ & & \\
\hline Well & $84.50 \pm 10.11$ & & \\
\hline
\end{tabular}

Notes: ${ }^{a} t ;{ }^{b} F ; \chi^{c}$.

a certain extent. ${ }^{40}$ Thus, it is recommended that steps for operating intelligent technology should be simple as possible. ${ }^{41}$ Only in this way would more older adults be willing to receive long-term care based on telenursing. In addition, through implementing time banking activities, this measure could provide disabled older adults with door-to-door application training, assistance, operations, etc., and provide optimal social support to promote increased acceptance of telenursing-based long-term care among disabled older adults.

Multiple linear regression analysis showed that educational level was also an important factor influencing the demands for telenursing-based long-term care. In this study, the educational levels of disabled older adults were relatively low, such as primary school, middle school and technical secondary school levels, which was consistent with the results of the investigation conducted by Yongyang Yan et al. ${ }^{42}$ Due to knowledge limitations, disabled older adults had shortcomings such as a poor ability to study and comprehend new information. ${ }^{43}$ Only a few disabled older adults had an undergraduate degree or higher, and most had attained only a middle school and technical secondary education. Thus, this population of older adults with low educational levels may need more telenursing-based long-term care to overcome their limitations. Disabled older adults with an undergraduate degree or higher were knowledgeable and had a wide range of ways to obtain health information, which affected their willingness to participate in telenursing-based long-term care to some extent. Therefore, long-term care facilities should adopt different guidance according to the different 
Table 4 Multiple Linear Regression Analysis of the Factors Influencing the Needs for Telenursing-Based Long-Term Care $(n=2 \mid 3)$

\begin{tabular}{|l|c|c|c|c|c|}
\hline $\begin{array}{l}\text { Independent } \\
\text { Variable }\end{array}$ & $\boldsymbol{\beta}$ & SE & $\boldsymbol{\beta}$, & $\boldsymbol{t}$ & $\boldsymbol{P}$ \\
\hline Constant & 80.866 & 4.799 & - & 16.852 & $<0.00 \mathrm{I}$ \\
\hline Age & 2.564 & 0.870 & 0.196 & 2.947 & 0.004 \\
\hline Educational level & -2.389 & 0.791 & -0.201 & -3.021 & 0.003 \\
\hline $\begin{array}{l}\text { Average family } \\
\text { income }\end{array}$ & 2.384 & 0.668 & 0.264 & 3.567 & $<0.001$ \\
\hline
\end{tabular}

Notes: $R^{2}=0.229, F=4.555, P<0.001$

education levels of disabled older adults, ${ }^{44}$ modify the language so that it is easy for local older adults to understand, and further improve the effectiveness of guidance.

Moreover, this study proved that income also affected the demands for telenursing-based long-term care for older adults with disabilities, which may be connected with the economic status of these adults. The income of these adults was so low that the conditions for seeking medical treatment were limited. ${ }^{45}$ Through the establishment of telenursing-based long-term care based on long-term care insurance, it was possible to reduce the care expenses of disabled older adults and provide them with protection regarding the fairness and accessibility of telenursingbased long-term care. ${ }^{46}$ Therefore, it is worthwhile to integrate telenursing with long-term care as soon as possible to effectively address the financial burden of disabled families in poor economic conditions.

\section{Limitations}

The present study had certain limitations. First, in regard to the self-report questionnaires applied in this study, it was impossible to avoid subjective bias while reflecting on the demands for telenursing-based long-term care for disabled older adults. Second, the influencing factors did not account for all factors in this study. Future studies with large sample sizes can pay attention to other underlying factors that may affect the demands for telenursing-based long-term care in disabled older adults.

\section{Conclusion}

The demands for telenursing-based long-term care for disabled older adults were found to be high. It is worth focusing on combining telenursing and long-term care to provide effective, preferential and convenient care for disabled older adults. The findings demonstrated the significance of age, educational level and average family income factors in promoting the demand for telenursingbased long-term care in disabled older adults. Thus, long-term care facilities should formulate appropriate care methods for disabled older adults of different ages, educational levels, and average family incomes. Only in this way can more disabled older adults obtain better care and improved quality of life for their families.

\section{Ethical Considerations}

Ethical approval was obtained from the Affiliated Hospital of Qingdao University's research ethics committee (QYFY WZLL 25936). Since the surveyed community did not have an ethics committee, we obtained ethical approval from the hospital responsible for the health of disabled older adults, and all participation was voluntary and anonymous. This study was conducted in accordance with the Declaration of Helsinki.

\section{Acknowledgments}

We would like to acknowledge and thank all the participants in this study.

\section{Author Contributions}

$\mathrm{Yu} \mathrm{Wu}$ and Yuxiu Liu contributed equally to this work.

The authors contributed to the study as follows: $\mathrm{Yu} \mathrm{Wu}$ and Yuxiu Liu designed the study. Zhe $\mathrm{Su}, \mathrm{Yu} \mathrm{Wu}$ and Songwei Sun collected and analyzed the data. Yu Wu, Cuiping Liu, Wei Ding and Yufang Gao cowrote the article. All authors contributed to the data analysis, drafted or revised the article, agreed on the journal to which the article would be submitted, gave final approval of the version to be published, and agreed to be accountable for all aspects of the work.

\section{Funding}

This study was supported by the National Natural Science Foundation of China Youth Project (71804129) and the Qingdao Philosophy and Social Science Planning Project (QDSKL1901090).

\section{Disclosure}

The authors declare no conflicts of interest that require clarification. 


\section{References}

1. Low JA, Toh HJ, Tan LLC, et al. The nuts and bolts of utilizing telemedicine in nursing homes - the gericare@north experience. $J$ Am Med Dir Assoc. 2020;21(8):1073-1078. doi:10.1016/j. jamda.2020.04.014

2. National Bureau of Statistics. Seventh national census; 2021. Available from: http://www.stats.gov.cn/ztjc/zdtjgz/zgrkpc/dqcrkpc/ ggl/202105/t20210519_1817698.html. Accessed August 27, 2021.

3. Zhang LW, Fang Y. Prediction of the scale of disability and the cost of care for the elderly in my country's urban and rural areas from 2020 to 2050. China Health Stat. 2021;38(01):39-42.

4. Qingdao municipal bureau of statistics. Seventh national census of Qingdao; 2021. Available from: http://qdtj.qingdao.gov.cn/n28356045/ n32561056/n32561070/index.html. Accessed August 27, 2021.

5. Wang Y, Li GF, He Q. Meta integration of the qualitative research on the care experience of the disabled elderly caregivers. Nurs Res. 2021;35(09):1580-1587.

6. Naruse T, Matsumoto H, Fujisaki-sakai M, et al. Measurement of special access to home visit nursing services among Japanese disabled elderly people: using GIS and claim data. BMC Health Serv Res. 2017;17(1):377. doi:10.1186/s12913-017-2322-0

7. National Healthcare Security Administration and the Ministry of Finance. The guiding opinions on expanding the pilot program of long-term care insurance system; 2021. Available from: http://www.nhsa.gov.cn/art/ 2020/9/16/art_14_3584.html. Accessed August 27, 2021.

8. World Health Organization. Lessons for long-term care policy; 2002. Available from http://apps.who.int/iris/bitstream/10665/67275/1/ WHO_NMH7CCL_02.1.pdf. Accessed August 27, 2021.

9. World Health Organization. A glossary of terms for community health care and services for older persons; 2004. Available from: http://www.who.int/kobe_centre/ageing/ahp_vol5_glossary.pdf. Accessed August 27, 2021.

10. Chinese Nursing Management. Industry dynamic. Chin Nurs Manag. 2019;19:158

11. Meunier-Sham J, Preiss RM, Petricone R, et al. Laying the Foundation for the National TeleNursing Center: integration of the Quality-Caring Model Into TeleSANE Practice. J Forensic Nurs. 2019;15(3):143-151. doi:10.1097/JFN.0000000000000252

12. Yuan Y, Liu Y, Gong L, et al. Demand Analysis of Telenursing for Community-Dwelling Empty- Nest Elderly Based on the Kano Model. Telemed J E Health. 2021;27(4):414-421. doi:10.1089/ tmj.2020.0037

13. Zulfiqar AA, Hajjam A, Andres E. Focus on the Different Projects of Telemedicine Centered on the Elderly In France. Curr Aging Sci. 2019;11(4):202-215. doi:10.2174/1874609812666190304115426

14. Read Paul L, Salmon C, Sinnarajah A, et al. Web-based videoconferencing for rural palliative care consultation with elderly patients at home. Support Care Cancer. 2019;27(9):3321-3330. doi:10.1007/ s00520-018-4580-8

15. Hermes E, Burrone L, Perez E, et al. Implementing Internet-Based Self-Care Programs in Primary Care: qualitative Analysis of Determinants of Practice for Patients and Providers. JMIR Ment Health. 2018;5(2):e42. doi:10.2196/mental.9600

16. Hewitt S, Apps L, Bankart J, et al. Interactive web-based pulmonary rehabilitation programme: a randomised controlled feasibility trial BMJ Open. 2017;7(3):e013682. doi:10.1136/bmjopen-2016-013682

17. de Veer AJ, Peeters JM, Brabers AE, et al. Determinants of the intention to use e-Health by community dwelling older people. BMC Health Serv Res. 2015;15:103. doi:10.1186/s12913-015-0765-8

18. Xu WX, Cao SM, Tang XM, et al. A qualitative study on the experience of obtaining online care information for caregivers of the disabled elderly. J Nursing Sci. 2020;35(22):92-95.
19. Zhang X, Yu P, Yan J, et al. Using diffusion of innovation theory to understand the factors impacting patient acceptance and use of consumer e-health innovations: a case study in a primary care clinic. BMC Health Serv Res. 2015;15:71. doi:10.1186/s12913015-0726-2

20. Bujnowska-Fedak MM, Mastalerz-Migas A. Usage of medical internet and e-health services by the elderly. Adv Exp Med Biol. 2015;834:75-80. doi:10.1007/5584_2014_74

21. Seifert A, Batsis JA, Smith AC. Telemedicine in Long-Term Care Facilities During and Beyond COVID-19: challenges Caused by the Digital Divide. Front Public Health. 2020;8:690. doi:10.3389/ fpubh.2020.601595

22. Sun X, Yan W, Zhou H, et al. Internet use and need for digital health technology among the elderly: a cross-sectional survey in China. BMC Public Health. 2020;20(1):1386. doi:10.1186/s12889-02009448-0

23. Steinbeisser K, Grill E, Holle R, et al. Determinants for utilization and transitions of long-term care in adults $65+$ in Germany: results from the longitudinal KORA-Age study. BMC Geriatr. 2018;18 (1):172. doi:10.1186/s12877-018-0860-x

24. Bach RL, Wenz A. Studying health-related internet and mobile device use using web logs and smartphone records. PLoS One. 2020;15(6):e234663. doi:10.1371/journal.pone. 0234663

25. Crouch E, Gordon NP. Prevalence and Factors Influencing Use of Internet and Electronic Health Resources by Middle-Aged and Older Adults in a US Health Plan Population: cross-Sectional Survey Study. JMIR Aging. 2019;2(1):e11451. doi:10.2196/11451

26. Borowiak E, Kostka T. Comparative characteristics of the home care nursing services used by community-dwelling older people from urban and rural environments. J Adv Nurs. 2013;69(6):1259-1268. doi:10.1111/j.1365-2648.2012.06113.x

27. Slobbe L, Wong A, Verheij RA, et al. Determinants of first-time utilization of long-term care services in the Netherlands: an observational record linkage study. BMC Health Serv Res. 2017;17(1):626. doi:10.1186/s12913-017-2570-z

28. Zhang L, Zeng Y, Fang Y. The effect of health status and living arrangements on long term care models among older Chinese: a cross-sectional study. PLoS One. 2017;12(9):e182219. doi:10.1371/ journal.pone.0182219

29. Zhang L, Zeng Y, Wang L, et al. Urban-Rural Differences in Long-Term Care Service Status and Needs Among Home-Based Elderly People in China. Int J Environ Res Public Health. 2020;17 (5). doi:10.3390/ijerph17051701

30. Chen N, Li X, Yuan N, et al. Utilization willingness of institutional care between disabled and non-disabled seniors: evidence from Jiangsu, China. BMC Health Serv Res. 2019;19(1):410. doi:10.1186/s12913-019-4259-y

31. Meng D, Xu G, Davidson PM. Perceived unmet needs for community-based long-term care services among urban older adults: a cross sectional study. Geriatr Nurs. 2021;42(3):740-747. doi:10.1016/j.gerinurse.2021.03.013

32. Xin Y, Nie WB, Yue C, et al. Application progress of remote nursing in home care in the era of "Internet +". Chin J Modern Nurs. 2017;23 (06):873-877.

33. Trigo TR, de Freitas CCS, Wang YP, et al. The Influence of Depression on the Psychometric Properties of the Maslach Burnout Inventory-Human Services Survey: a Cross-Sectional Study With Nursing Assistants. Front Psychiatry. 2018;9:695. doi:10.3389/fpsyt.2018.00695

34. Qingdao Municipal Medical Insurance Bureau. The Notice of six longterm care insurance standards including the "Operation Procedures for Care Level Assessment in Long-term Care Insurance"; 2020. Available from: http://ybj.qingdao.gov.cn/n28356081/n32567782/n32567784/ n32567942/200601161039017040.html. Accessed August 27, 2021. 
35. Wu FQ, Fan H, Xiao SQ. The care needs and influencing factors of disabled elderly in Beijing communities. Chin J Nurs. 2018;53 (07):841-845.

36. National Health and Family Planning Commission. Notice of the National Health and Family Planning Commission on Printing and Distributing the National Nursing Career Development Plan (20162020); 2021. Available from: http://www.nhc.gov.cn/cms-search/xxgk/ getManuscriptXxgk.htm?id=92b2e8f8cc644a899e9d0fd572aefef3.

37. Chen WS, Hsu HC, Chuang YW, et al. Predictors for the use of traditional Chinese medicine among inpatients with first-time stroke: a population-based study. BMC Complement Med Ther. 2020;20 (1):244. doi:10.1186/s12906-020-03037-9

38. Zheng G, Fang Q, Chen B, et al. Qualitative Evaluation of Baduanjin (Traditional Chinese Qigong) on Health Promotion among an Elderly Community Population at Risk for Ischemic Stroke. Evid Based Complement Alternat Med. 2015;2015:893215. doi:10.1155/2015/ 893215

39. Baudin K. Gustafsson C and Frennert S. Views of Swedish Elder Care Personnel on Ongoing Digital Transformation: cross-Sectional Study. J Med Internet Res. 2020;22(6):e15450. doi:10.2196/15450

40. Jia YJ, Wang C. The construction of a demand-oriented smart home care service system. Inner Mongolia Social Sci. 2020;41(05):166$172+213$.
41. Cameron P, Munyan K. Systematic Review of Telehospice Telemedicine and e-Health. Telemed J E Health. 2021. doi:10.1089/ tmj.2020.0451.

42. Yan YY, Deng J, Sun HY. Study on the Cognition and Needs of "Internet + Nursing Services" in Patients with Chronic Diseases. J Nurs Manag. 2020;20(11):803-808.

43. Wang Y, Liu Y, Tian J, et al. Analysis on nursing competence and training needs of dementia caregivers in long-term care institutions. Int J Nurs Sci. 2020;7(2):198-205.

44. Alcazar B, Ambrosio L. [Tele-nursing in patients with chronic illness: a systematic review]. An Sist Sanit Navar. 2019;42(2):187-197. Spanish.

45. Cui C, Wang K, An J, et al. Current status and influencing factors of post-traumatic growth in maintenance hemodialysis. Int J Nurs Sci. 2017;4(4):362-366.

46. Bradford NK, Caffery LJ, Caffery SAC, Smith AC. Telehealth services in rural and remote Australia: a systematic review of models of care and factors influencing success and sustainability. Rural Remote Health. 2016;16(4):3808.
Patient Preference and Adherence

\section{Publish your work in this journal}

Patient Preference and Adherence is an international, peer-reviewed, open access journal that focusing on the growing importance of patient preference and adherence throughout the therapeutic continuum. Patient satisfaction, acceptability, quality of life, compliance, persistence and their role in developing new therapeutic modalities and compounds to optimize clinical outcomes for existing disease
Dovepress

states are major areas of interest for the journal. This journal has been accepted for indexing on PubMed Central. The manuscript management system is completely online and includes a very quick and fair peer-review system, which is all easy to use. Visit http:// www.dovepress.com/testimonials.php to read real quotes from published authors. 